\title{
Plastic Deformation Behavior of Sintered Fe-Based Alloys for Light-Weight Automotive Components
}

\author{
Yohan Kang, Suchul Yoon, Minwook Kim, and Seok-Jae Lee* \\ Division of Advanced Materials Engineering, Chonbuk National University, Jeonju 561-756 \\ (Received May 7, 2014, Revised May 28, 2014, Accepted May 30, 2014)
}

\begin{abstract}
We investigated the effects of the chemical composition and the relative density on the plastic deformation behavior of sintered Fe-based alloys by means of compressive tests. Overall compressive stresses increased as the amount of alloying elements and the relative density were respectively increased. Addition of alloying elements except for Mo increased the yield stress regardless of the relative density. The relationship between the effects of the chemical composition and the relative density and the mean rate of the stress increase was analyzed. A constitutive equation based on the Ludwik equation with the regressed parameters was proposed to predict the compressive true stress-true strain curves of the sintered Fe-based alloys. The $\mathrm{K}$ and $\mathrm{n}$ values used in the proposed equation were regressed as a function of the alloying elements and the relative density based on the individual $\mathrm{K}$ and $\mathrm{n}$ values. The plastic deformation behavior predicted using the proposed constitutive equation showed reliable accuracy compared with experimental data.
\end{abstract}

Keywords : Sintered Fe-based alloys, Constitutive equation, Alloying element, Relative density, Light-weight automotive component

\section{Introduction}

The development of energy-saving materials has become a key focus in automotive industries. Global automobile manufacturers have tried to increase the use of light-weight alloys such as aluminum alloys and magnesium alloys instead of $\mathrm{Fe}$-based alloys, which are mainly used in cars [1]. However, the use of both aluminum and magnesium alloys is limited due to their relatively lower strength compared to $\mathrm{Fe}$-based alloys. One solution to overcome the limitation of using these light-weight alloys for the purpose of energy savings is the manufacture of $\mathrm{Fe}$-based automotive components fabricated by powder metallurgy (PM) processes [2-4]. Sintered materials manufactured by PM processes are characterized by lower density due to their porosity, which can contribute to weight reduction. Other advantages obtained from the use of sintered materials or components include 1) increased precision of components, resulting in a reduction of extra processes after heat treatment due to unexpected distortion and less material loss; and 2) precise control over the alloying composition by simple mixing and milling.

Sintered $\mathrm{Fe}$-based components have been used as substitutes for steel components manufactured by conventional methods due to the higher precision of

\footnotetext{
* [E-mail] seokjaelee@jbnu.ac.kr
} 
sintered parts. As sintered Fe-based alloys are a potential new candidate for energy-saving materials in the automotive industry, there has been renewed interest in investigation of multi-functional $\mathrm{Fe}$-based alloys. Satisfactory mechanical properties are essential for automotive components, and in this context the hardness and wear resistance of sintered Fe-based alloys have been widely investigated [5-7]. However, little is known about the plastic deformation behavior of these alloys. In the present study, we investigated the plastic deformation behavior of various Fe-based alloys manufactured by PM processes. The effects of alloying element addition and relative density on the compressive stress-strain curves of sintered $\mathrm{Fe}$-based alloys were studied and a new constitutive model that takes into consideration the effects of alloying elements and density was proposed.

\section{Experimental Procedure}

The chemical composition of the alloys used in this study is listed in Table 1. The alloy elements $\mathrm{Ni}, \mathrm{Cr}$, and Mo for low alloy steels, which are mainly used for automotive components, were considered. Also, the

Table 1. Chemical composition of sintered Fe-based alloys (wt.\%).

\begin{tabular}{l|c|c|c|c|c}
\hline \hline Alloy & $\mathrm{C}$ & $\mathrm{Ni}$ & $\mathrm{Cr}$ & $\mathrm{Mo}$ & $\mathrm{Fe}$ \\
\hline $\mathrm{C} 20$ & 0.2 & 0.0 & 0.0 & 0.0 & bal. \\
\hline $\mathrm{C} 40$ & 0.4 & 0.0 & 0.0 & 0.0 & bal. \\
\hline $\mathrm{C} 60$ & 0.6 & 0.0 & 0.0 & 0.0 & bal. \\
\hline $\mathrm{NiL}$ & 0.2 & 0.5 & 0.0 & 0.0 & bal. \\
\hline $\mathrm{NiH}$ & 0.2 & 1.0 & 0.0 & 0.0 & bal. \\
\hline $\mathrm{CrL}$ & 0.2 & 0.0 & 0.5 & 0.0 & bal. \\
\hline $\mathrm{CrH}$ & 0.2 & 0.0 & 1.0 & 0.0 & bal. \\
\hline $\mathrm{MoL}$ & 0.2 & 0.0 & 0.0 & 0.5 & bal. \\
\hline $\mathrm{MoH}$ & 0.2 & 0.0 & 0.0 & 1.0 & bal. \\
\hline $\mathrm{NiCr}$ & 0.2 & 1.0 & 1.0 & 0.0 & bal. \\
\hline $\mathrm{CrMo}$ & 0.2 & 0.0 & 1.0 & 1.0 & bal. \\
\hline $\mathrm{NiMo}$ & 0.2 & 1.0 & 0.0 & 1.0 & bal. \\
\hline NiCrMo & 0.2 & 1.0 & 1.0 & 1.0 & bal. \\
\hline
\end{tabular}

amount of $\mathrm{C}$ was varied based on the consideration that the C level at the surface is increased when a carburizing process is applied for surface hardening. The designed mass of $\mathrm{Fe}, \mathrm{Ni}, \mathrm{Cr}$, Mo, and graphite powders was precisely weighed and mixed in a Turbular mixer for $30 \mathrm{~min}$ to obtain a homogenized powder mixture. The homogeneously mixed powders were compacted with pressures of $500 \mathrm{MPa}$ and $850 \mathrm{MPa}$ using a hydraulic press. Cylindrical samples of $11 \mathrm{~mm}$ diameter and $10 \mathrm{~mm}$ height were obtained. These green compacts were sintered at $1150^{\circ} \mathrm{C}$ for $30 \mathrm{~min}$ in a $\mathrm{N}_{2}+10 \% \mathrm{H}_{2}$ atmosphere to prevent oxidation and any other surface reactions. The samples were then furnace cooled to room temperature.

The Archimedes principle was used to measure the densities of the compacted samples and sintered samples [8]. The measured density of the compacted samples was about $5.4 \mathrm{~g} / \mathrm{cm}^{3}$ under a pressure of $500 \mathrm{MPa}$ and about 6.3 $\mathrm{g} / \mathrm{cm}^{3}$ under a pressure of $850 \mathrm{MPa}$, respectively. The sample density after the sintering was about $6.4 \mathrm{~g} / \mathrm{cm}^{3}$ under a pressure of $500 \mathrm{MPa}$ and about $6.9 \mathrm{~g} / \mathrm{cm}^{3}$ under a pressure of $850 \mathrm{MPa}$, respectively. The values of the measured densities were critically dependent on the compact pressure, regardless of the addition of alloying elements, because the total amount of added alloying elements was less than 3wt.\%, as seen in Table 1. To convert the measured density to relative density, the theoretical density is required. The theoretical density of ferritic $\mathrm{Fe}$-based alloys at room temperature $\left(\mathrm{g} / \mathrm{cm}^{3}\right)$ can be calculated by using the following equation [9].

$$
\begin{aligned}
\rho_{\alpha}= & (1.270 \mathrm{Fe}+1.380 \mathrm{C}+1.524 \mathrm{Mn}+2.381 \mathrm{Si} \\
& +1.370 \mathrm{Ni}+1.384 \mathrm{Cr}+1.076 \mathrm{Mo})^{-1} \times 10^{3}
\end{aligned}
$$

where the amount of each alloy is in wt.\%. The relative density of the sintered samples was calculated to be about $80 \%$ for a compact pressure of $500 \mathrm{MPa}$ and about $90 \%$ for a compact pressure of $850 \mathrm{MPa}$, respectively.

Compressive tests were carried out using a universal testing machine at a a strain rate of $10^{-3} \mathrm{~s}^{-1}$. Typically, a true stress-true strain curve is required to derive a 
constitutive equation. The compressive load was measured as the height of a sample was decreased during the compressive test. The true compressive stress $(\rho)$ and the true compressive strain $(\varepsilon)$ can be converted from the measured compressive load and the sample height as follows:

$$
\begin{aligned}
& \sigma=\frac{4 F h}{\pi D_{0}^{2} h_{0}} \\
& \varepsilon=\ln \frac{h_{0}}{h}
\end{aligned}
$$

where $F$ denotes a compressive load, $D_{0}$ is the initial cross sectional area of the sample, $h_{0}$ is the initial height of the sample, and $h$ refers to the actual height of the sample during compression.

\section{Results and Discussion}

The microstructures of the sintered samples (C20 alloy
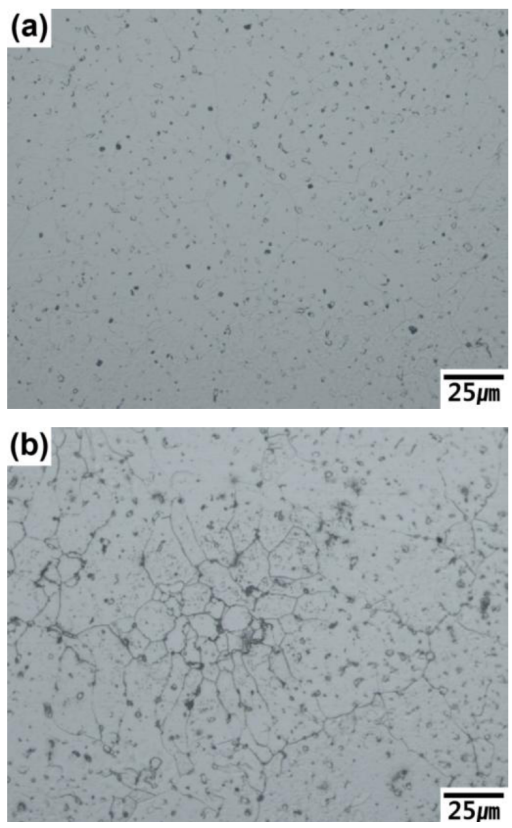

Figure 1. Optical micrographs of the (a) C20 and (b) $\mathrm{NiCrMo}$ alloy samples with relative density of $90 \%$. $2 \%$ nital etchant was used. and NiCrMo alloy) are shown in Fig. 1. A ferrite-pearlite microstructure commonly appears due to slow furnace cooling from $1,150^{\circ} \mathrm{C}$ regardless of the kinds of added alloying elements. However, a microstructure with more fine grains was observed in the NiCrMo sample, which contains Ni, Cr, and Mo. Some parts with spherical shapes were distinguishable from the matrix, and they are thought to be particles of $\mathrm{Ni}, \mathrm{Cr}$, and $\mathrm{Mo}$ or carbides formed during the sintering process. While the samples prepared simply by mixing alloy powders were used to investigate the plastic deformation behavior of the sintered alloy samples in the present study, many studies in the powder metallurgy field employ grain refinement by using a high energy ball mill [10,11]. The authors are currently studying the influence of powder size and grain refinement on the mechanical properties of sintered Fe-based alloys.

Fig. 2 compares the true stress-true strain curves according to the relative density of the sintered alloy samples and the added alloying elements. Compared with the stress-strain curves of the C20 alloy, the compressive stress of other alloy samples increased as the relative density and the amount of alloying elements were respectively increased. The improvement of mechanical properties due to increased density has been reported for many other sintered metals.

Fig. 3 compares the variation of the yield stress according to the chemical composition. It is known that the addition of alloying elements generally increases the strength of metals by strengthening mechanisms such as solid-solution strengthening or dispersion strengthening due to the formation of a secondary phase. The same strengthening effects by adding alloying elements are confirmed in the PM alloy steels in Fig. 3. The addition of $\mathrm{C}$ to the $\mathrm{C} 20$ alloy with a relative density of $80 \%$ showed the greatest effect in terms of increasing the yield stress, as shown in Fig. 3(a). This is in agreement with experimental results by Pickering [12]. He reported that $\mathrm{C}$ addition led to an increased volume fraction of pearlite in ferrite-pearlite microstructural steels, thereby more 

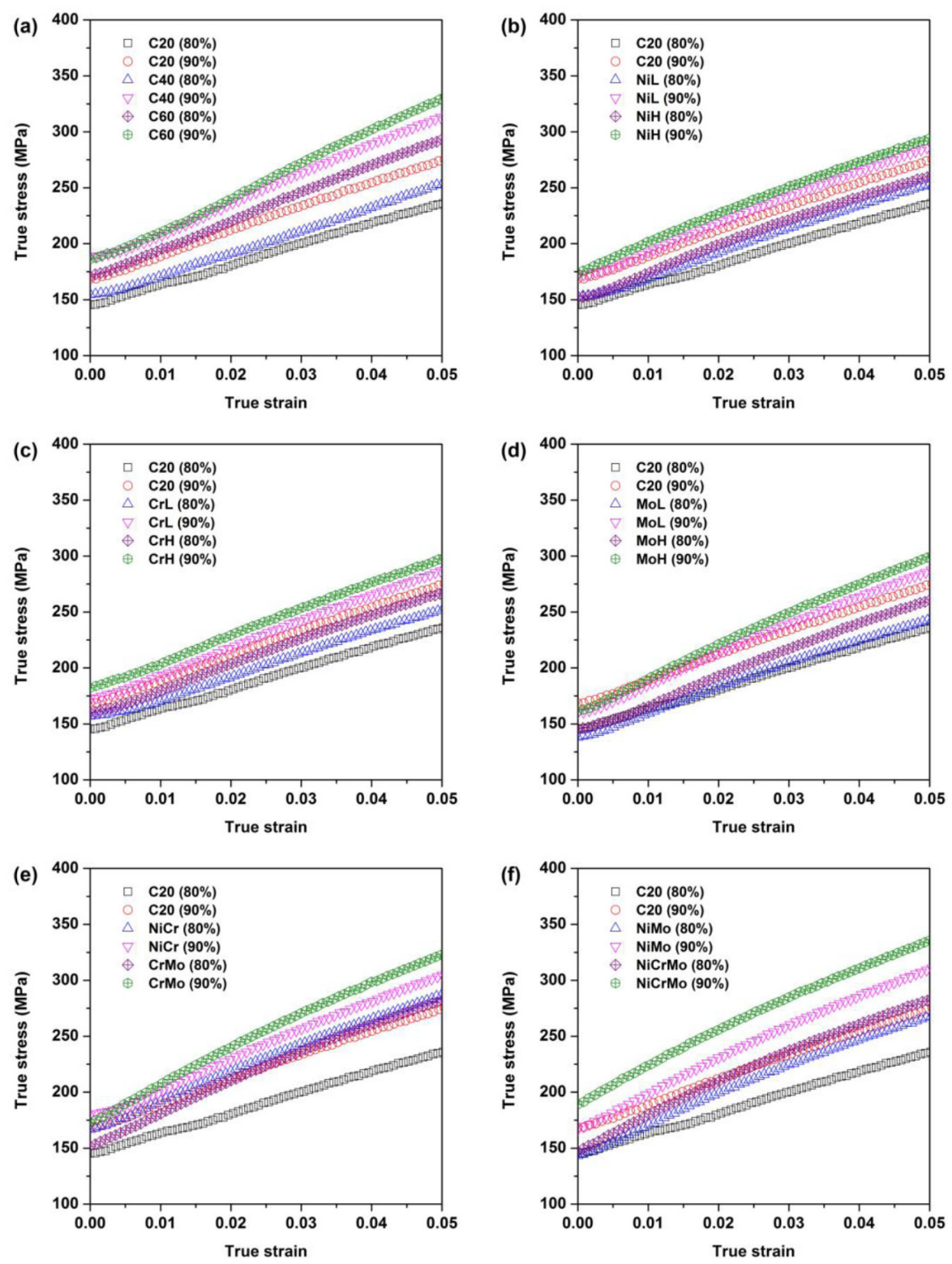

Figure 2. Effects of alloying elements on true stress-strain curves of sintered alloy steels with different relative densities (80 and 90\%) under compression at room temperature: (a) C effect, (b) Ni effect, (c) Cr effect, (d) Mo effect, (e) complex alloying effect ( $\mathrm{Ni}-\mathrm{Cr}, \mathrm{Cr}-\mathrm{Mo}$ ), and (f) complex alloying effect ( $\mathrm{Ni}-\mathrm{Mo}$, $\mathrm{Ni}-\mathrm{Cr}-\mathrm{Mo}$ ).

effectively increasing the yield stress compared to adding other alloying elements. The additions of $\mathrm{Ni}$ and $\mathrm{Cr}$ increase the yield stress whereas Mo addition decreases the yield stress. Hodgson and Gibbs [13] reported that the additions of Mn, Si, P, and Cu increased the yield stress. It was also reported that the tensile strength was increased by adding $\mathrm{Ni}, \mathrm{Cr}$, and Mo in acicular ferrite and low C bainite [14]. However, to date, no reports have quantified the relation between the additions of $\mathrm{Ni}, \mathrm{Cr}$, and Mo and the yield strength. The additions of $\mathrm{Cr}$ and $\mathrm{Ni}$ show positive effects on the increase of the yield stress, and thus the $\mathrm{NiCr}$ alloy shows a higher yield stress value among complex alloying samples. When Mo is added with other alloying elements, its negative effect on increasing 

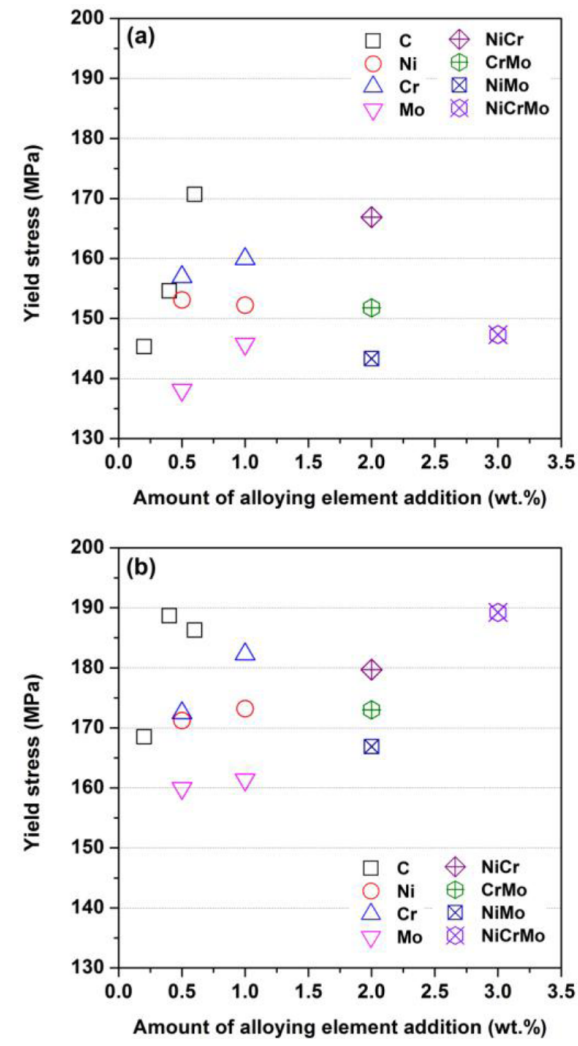

Figure 3. Effect of alloying element addition on yield stress of sintered alloy steels with different relative densities: (a) $80 \%$ and (b) $90 \%$.

the yield stress is intensified and this suppresses the improvement of the yield stress with $\mathrm{Cr}$ or Ni addition. The effect of Mo addition can be confirmed by comparing the yield stress of the NiCrMo sample, which is similar to that of the C20 sample. Similar experimental results were observed for the samples with a relative density of $90 \%$, as seen in Fig. 3(b). The yield stress increased as the relative density was increased from $80 \%$ to $90 \%$. Carbon appears to be the most effective element to increase the yield stress, and $\mathrm{Cr}$ and $\mathrm{Ni}$ also exert positive effects. The addition of Mo alone or with other elements, however, prevented the increase of the yield stress. Nonetheless, the NiCrMo alloy with a relative density of $90 \%$ recorded a higher yield stress than the other alloys, although the yield stress of the NiCrMo alloy is lower than that of the $\mathrm{NiCr}$ alloy due to the negative effect of Mo addition. One possible reason that the maximum yield stress was attained is grain

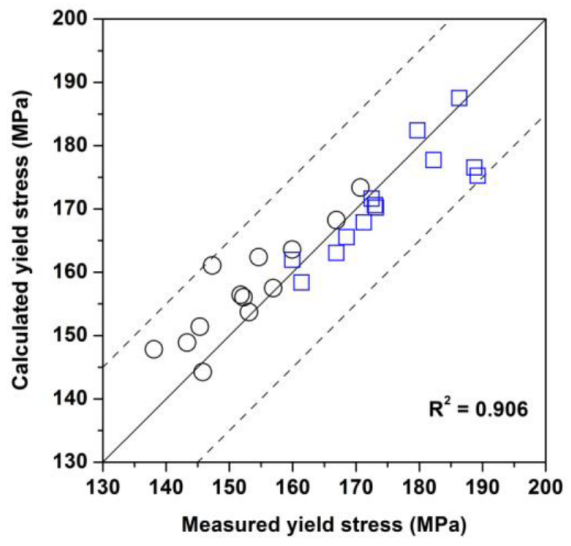

Figure 4. Comparison of measured and calculated yield stress for sintered alloy steels with different relative densities. The black circular symbols indicate the samples with relative density of $80 \%$ and the blue rectangular symbols indicate the samples with relative density of $90 \%$.

refinement by adding complex alloying elements. In addition, the Hall-Petch relationship is effectively activated as the relative density reaches a critical value. In this work about 90\% relative density was sufficient to trigger the Hall-Petch effect. More in-depth investigation is required to reveal the relationship between the relative density and the Hall-Petch effect in PM alloy steels.

The influence of the addition of alloying elements and the relative density on the yield stress can be expressed by the following relationship.

$$
\begin{aligned}
\sigma_{Y S}= & -40.65+54.95 \mathrm{C}+4.66 \mathrm{Ni} \\
& +12.19 \mathrm{Cr}-7.16 \mathrm{Mo}+220.67 \rho
\end{aligned}
$$

where the amount of alloying element is given in wt.\% and $\rho$ denotes the relative density of the sample. Fig. 4 shows the accuracy of the yield stress predicted by using Eq. (4) compared with the experimental data. Relatively high accuracy is confirmed by a high $R^{2}$ value $\left(R^{2}=0.906\right)$. Also, higher relative density is related with higher yield stress,

Fig. 5 compares the effects of the addition of alloying elements and the relative density on the mean rate of stress 

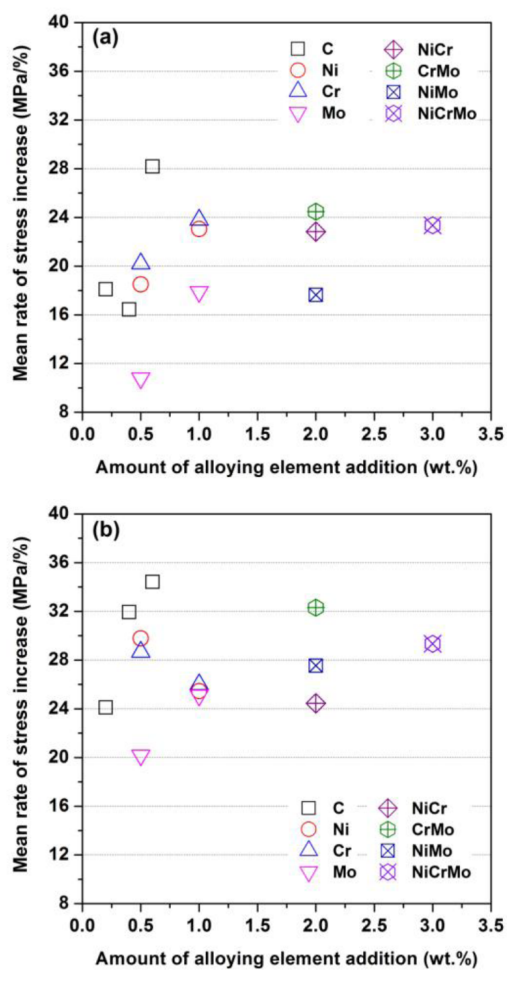

Figure 5. Effect of the amount of alloying element on the mean rate of stress increase for sintered alloy steels with different relative densities: (a) $80 \%$ and (b) $90 \%$.

increase up to a plastic strain of $5 \%$. The stress increase rate was increased by roughly $40 \%$ with increased density. The addition of $\mathrm{C}$ had the greatest impact on the mean rate of stress increase. In the case of the alloys with a relative density of $80 \%$, Mo addition lowered the mean rate of stress increase. But the CrMo alloy showed a higher mean rate of stress increase compared with the $\mathrm{NiCr}$ or NiMo alloys. Similar mean stress increase rates were observed by adding 1wt.\% Ni, Cr, and Mo, respectively, when the relative density was 90\%. Also, the CrMo and NiMo alloys that contain 1wt.\% Mo showed higher mean rates of stress increase than the NiCr alloy. However, regardless of the relative density, the mean rate of stress increase of the NiCrMo alloy was lower than that of the CrMo alloy. It is thought that the addition of $\mathrm{Ni}$ to the complex alloying system impeded the mean rate of stress increase.

A typical constitutive equation to describe the plastic deformation behavior is expressed given by,

$$
\sigma=\sigma(\varepsilon, \dot{\varepsilon}, T)=f(\varepsilon) \cdot g(\dot{\varepsilon}) \cdot h(T)
$$

where $\varepsilon$ is the strain, $\dot{\varepsilon}$ is the strain rate, and $T$ is the temperature. Thus, $f(\varepsilon)$ is the strain hardening term, $g(\dot{\varepsilon})$ is related to the strain rate sensitivity, and $h(T)$ indicates a thermal softening effect. Since we carried out the compressive test with a fixed strain rate at room temperature to observe the effects of the alloying element and density in this study, a simplified constitutive equation focused on the strain hardening phenomenon was considered. Several constitutive equations are used to demonstrate the strain hardening behavior, as given below.

Hollomon equation [15]: $\sigma=K \varepsilon^{n}$

Ludwik equation [16]: $\sigma=\sigma_{0}+K \varepsilon^{n}$

Swift equation [17]: $\sigma=K\left(\varepsilon+\varepsilon_{0}\right)^{n}$

Voce equation [18]: $\sigma=\sigma_{s}-\left(\sigma_{s}-\sigma_{0}\right) \exp (-n \varepsilon)$

Ludwigson equation [19]: $\sigma=K_{1} \varepsilon^{n_{1}}+\exp \left(K_{2}+n_{2} \varepsilon\right)$

where $\sigma_{0}$ is the yield stress, $\varepsilon_{0}$ is the basic strain, $\sigma_{\mathrm{s}}$ is the saturated stress, $K, K_{1}, K_{2}$ are the material constants, and $n, n_{1}$, and $n_{2}$ are values related to the work hardening exponent. In the present work, the Ludwik equation was adopted to describe the compressive stress-strain relationship of the sintered alloys considering the variation of the yield stress together. Only Ludwik equation (Eq. (7)) and Voce equation (Eq. (9)) can show a yield stress directly in each equation, which was important since the yield stress was influenced by alloying element and density as shown in Fig. 3. A saturated stress should be known to demonstrate the flow curve by using Eq. (9), but the saturated stress is commonly obtained by tensile test, not compressive test. Thus, Eq. (7) was selected to predict the stress-strain curves with a consideration of the variation of yield stress together.

The values of $\mathrm{K}$ and $\mathrm{n}$ used in the Ludwik equation were obtained from the compressive true stress-true strain curve of each alloy sample, and then the simple equations for $\mathrm{K}$ and $\mathrm{n}$ were regressed as a function of the alloying 

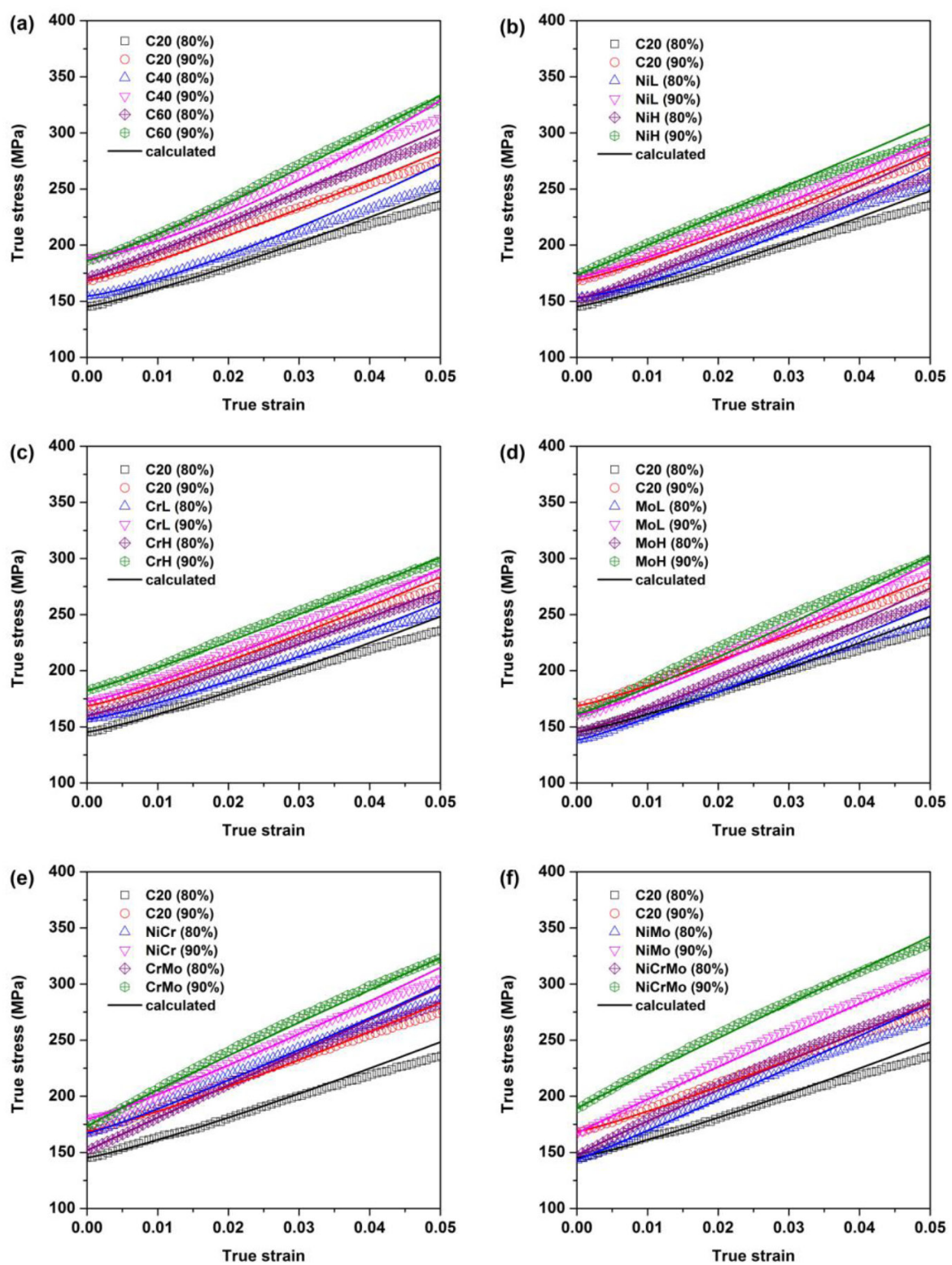

Figure 6. Comparison of the experimental stress-strain curve and the predicted stress-strain curve considering the effects of relative density and alloying elements: (a) C effect, (b) Ni effect, (c) Cr effect, (d) Mo effect, (e) complex alloying effect ( $\mathrm{Ni}-\mathrm{Cr}, \mathrm{Cr}-\mathrm{Mo}$ ), and ( $\mathrm{f}$ ) complex alloying effect ( $\mathrm{Ni}-\mathrm{Mo}, \mathrm{Ni}-\mathrm{Cr}-\mathrm{Mo}$ ).

element and relative density as follows.

$$
\begin{aligned}
K & =97722.5-643174 \mathrm{C}+764343 \mathrm{C}^{2}+73551 \mathrm{Ni}-53983 \mathrm{Ni}^{2} \\
& +25690 \mathrm{Cr}-23990 \mathrm{Cr}^{2}-45675 \mathrm{Mo}+49525 \mathrm{Mo}^{2}-20914 \mathrm{NiCr} \\
& -13479 \mathrm{NiMo}+1931 \mathrm{CrMo}-\left(122653-834535 \mathrm{C}+995369 \mathrm{C}^{2}\right. \\
& +78268 \mathrm{Ni}-54019 \mathrm{Ni}^{2}+27007 \mathrm{Cr}-24589 \mathrm{Cr}^{2} \\
& -55243 \mathrm{Mo}+59172 \mathrm{Mo}^{2}-25559 \mathrm{NiCr} \\
& -14658 \mathrm{NiMo}+3277 \mathrm{CrMo}) \rho
\end{aligned}
$$

$$
\begin{aligned}
n= & 4.074-17.68 \mathrm{C}+18.39 \mathrm{C}^{2}+4.09 \mathrm{Ni} \\
& -1.89 \mathrm{Ni}^{2}+2.80 \mathrm{Cr}-2.90 \mathrm{Cr}^{2}-3.49 \mathrm{Mo}+3.75 \mathrm{Mo}^{2}-1.89 \mathrm{NiCr} \\
& -1.20 \mathrm{NiMo}+0.22 \mathrm{CrMo}-\left(4.09-25.23 \mathrm{C}-18.39 \mathrm{C}^{2}+4.24 \mathrm{Ni}\right. \\
& -2.16 \mathrm{Ni}^{2}+3.01 \mathrm{Cr}-3.06 \mathrm{Cr}^{2}-4.06 \mathrm{Mo}+4.40 \mathrm{Mo}^{2}-2.34 \mathrm{NiCr} \\
& -1.35 \mathrm{NiMo}+0.38 \mathrm{CrMo}) \rho
\end{aligned}
$$

where the amount of alloying element is in wt.\% and $\rho$ is the relative density of the sample. Fig. 6 compares the 
experimental compressive true stress-true strain curves and the predicted true stress-true strain curves considering the effects of the chemical composition and the relative density by using the $\mathrm{K}$ and $\mathrm{n}$ values calcualted from the regressed equations. The $R^{2}$ value, which indicates the accuracy of the regression analysis to obtain Eqs. (11) and (12) from individual $\mathrm{K}$ and $\mathrm{n}$ values, was 0.947 for Eq. (11) and 0.935 for Eq. (12), respectively. Even though these $R^{2}$ values appear to be relatively reliable, it is difficult to regress all individual $K$ and $n$ values in a single equation taking both the alloy effect and the density effect into account, because the alloy effect on the plastic deformation behavior varies irregularly with the density effect, as shown in Fig. 5. However, when we applied the individual values of $\mathrm{K}$ and $\mathrm{n}$ to describe eac compressive stress-strain curve, the average $R^{2}$ value was 0.991. This means that the individual values of $K$ and $n$ used to obtain Eqs. (11) and (12) can demonstrate the original stress-strain curves accurately. As the limitation to derive the Ludwik equation with the regressed parameters is considered, the overall predicted true stress-true strain curves describe the experimental compressive true stress-true strain curves acceptably well according to different chemical compositions and relative densities in sintered Fe-based alloys.

\section{Conclusions}

The effects of the chemical composition and the density on the plastic deformation behavior of sintered Fe-based alloys were investigated. The compressive stress increased as the amount of alloying elements and the relative density were respectively increased. The alloying elements, except for Mo, increased the yield stress regardless of the relative density. The mean rate of the stress increase showed an increasing trend with the addition of alloying elements. In particular, the addition of Mo to the complex alloying system is an effective means of increasing the mean rate of the stress increase, although no particular effect was observed by adding Mo solely. The Ludwik equation was adopted to derive the constitutive equation for predicting the true stress-true strain curves of sintered Fe-based alloys. The $\mathrm{K}$ and $\mathrm{n}$ values used in the Ludwik equation were regressed as a function of the alloying elements and the relative density based on the individual $K$ and $n$ values. The true stress-true strain curves predicted using the proposed constitutive equation agreed well with the experimental compressive curves. It is anticipated that the analysis results and proposed constitutive equation will be helpful to design new sintered Fe-based alloys for energy saving, light-weight automotive components.

\section{Acknowledgements}

This research was supported by Industry, University and Research Institute Core Technology Development \& Industrialized Supporting Business conducted by Jeonbuk Province in 2013.

\section{References}

[1] J. Hirsch and T. Al-Samman, Acta Mater. 61, 818 (2013).

[2] D. K. Park and Y. J. Kim, J. Kor. Pow. Metall. Inst. 13, 1 (2006).

[3] Z. Zhang and R. Sandström, J. Alloys Compd. 363, 194 (2004).

[4] D. Shanmugasundaram and R. Chandramouli, Mater. Des. 30, 3444 (2009).

[5] W. F. Wang, Mater. Sci. Eng. A 402, 92 (2005).

[6] J. Victoria-Hernández, D. Hernández-Silva, and M. Vite-Torres, Wear 267, 340 (2009).

[7] H. Zuhailawati, T. C. Geok, and P. Basu, Mater. Des. 31, 2211 (2010).

[8] M. E. Sotomayor, L. M. Ospina, B. Levenfeld, and A. Várez, Mater. Charac. 86, 108 (2013).

[9] U. Bohnenkamp and R. Sandström, Steel Res. 71, 88 
(2000).

[10] S. Gialanella, X. Amils, M. D. Barò, P. Delcroix, G. Le Caër, L. Lutterotti, and S. Suriñach, Acta Mater. 46, 3305 (1998).

[11] Y. Saberi, S. M. Zebarjad, and G. H. Akbari, J. Alloys Compd. 484, 637 (2009).

[12] F. B. Pickering, Towards Improvement Ductility and Toughness, (Climax Molybdenum Company, Tokyo, 1971), p. 9.

[13] P. D. Hodgson and R.K. Gibbs, ISIJ Inter. 32, 1329
(1992).

[14] F. B. Pickering, TISCO Silver Jubilee Jan-Oct, 105 (1980).

[15] J. H. Hollomon, Trans. AIME 162, 268 (1945).

[16] P. Ludwik, Elemente der Technologischen Mechanik, (Verlag Von Julius Springer, Leipzig, 1909) p. 32.

[17] H. W. Swift, J. Mech. Phys. Solids 1, 1 (1952).

[18] E. Voce, J. Inst. Met. 74, 537 (1948).

[19] D. C. Ludwigson, Metall. Trans. 2, 2825 (1971). 